\title{
ANÁLISE DE CUSTOS DA PRODUÇÃO DE LEITE: APLICAÇÃO DO MÉTODO DE MONTE CARLO
}

\author{
Omar Jorge Sabbag ${ }^{1}$ \\ Silvia Maria Almeida Lima Costa
}

\section{Resumo}

O Brasil é o quarto maior produtor de leite mundial e o estado de São Paulo responde por $5 \%$ da produção nacional. Neste Estado, $76,5 \%$ dos produtores são vinculados às associações ou cooperativas. Objetivou-se avaliar a rentabilidade da produção de leite para uma associação de produtores rurais da região da Alta Paulista, estimando, pelo método de Monte Carlo, a construção de cenários de parâmetros conjunturais da produção. As estimativas de custos foram baseadas no Custo Operacional Total utilizada pelo Instituto de Economia Agrícola/APTA/SAA/SP. Para a rentabilidade, foram realizadas 10.000 iterações com base nos indicadores de produção, custos e preços. Os resultados apontaram que o risco de insucesso, decorrente da distribuição de frequência do lucro operacional, foi de $28,23 \%$. O índice de lucratividade apresentou média de 10,12\%, revelando limitação da atividade, apontando para uma meta produtiva de no mínimo 6.075 litros mês $^{-1}$. Conclui-se que os insumos e mão de obra foram os principais condicionantes que limitaram o retorno econômico da atividade leiteira ser elevada, necessitando de esforços gerenciais e tecnológicos dos produtores.

Palavras-chave: bovinocultura de leite; rentabilidade; riscos.

\footnotetext{
${ }^{1}$ Graduado em Agronomia (UNESP). Mestrado em Sistemas de Produção (UNESP). Doutorado em Planejamento Ambiental e Desenvolvimento Regional (UNESP). Prof. Assistente Doutor I da UNESP. E-mail: sabbag@agr.feis.unesp.br

${ }^{2}$ Graduada em Agronomia (UNESP). Mestrado em Economia Agrária (ESALQ/USP). Doutorado em Economia Aplicada (ESALQ/USP). Profạ. Assistente Doutora II da UNESP.E-mail: smalcost@agr.feis.unesp.br
} 


\title{
COSTS ANALYSIS OF MILK PRODUCTION: APPLICATION OF MONTE CARLO METHOD
}

\begin{abstract}
Brazil is the world's fourth largest producer of milk and the São Paulo state accounts for $5 \%$ of the national production. In this state, $76.5 \%$ of producers are linked to associations or cooperatives. Aimed to evaluate the profitability of milk production for an association of farmers in the region of Alta Paulista, estimated by Monte Carlo method, the construction of scenarios of short-term parameters of associative production. The estimated costs were based on Total Operating Cost used by the Institute of Agricultural Economics/APTA/SAA/SP. To profitability, 10,000 iterations based on indicators of production, costs and prices. The results indicated that the risk of failure, due to the frequency distribution of operating income was $28.23 \%$. The profitability index had a mean of $10.12 \%$, revealing activity limitation, pointing to a production target of at least 6075 liters month ${ }^{-1}$. We conclude that the inputs and labor were the main constraints that have limited the economic return of dairy farming are high, requiring managerial and technological efforts of producers.
\end{abstract}

Key-words: dairy cattle; profitability; risks.

\section{INTRODUÇÃO}

O complexo agroindustrial leiteiro constitui-se em um dos mais importantes complexos do agronegócio brasileiro. Esta relevância não é explicada necessariamente pelo volume de oferta e geração de divisas, mas fundamentalmente pela importância do leite e derivados lácteos na composição da dieta alimentar humana.

Embora no cenário mundial o Brasil posicione-se como quarto maior produtor de leite, com uma produção de 32.380 mil toneladas, atrás da União Europeia, Índia e Estados Unidos (FERRAZ et. al., 2013), o quadro de suprimento projetado pelo Ministério da Agricultura para o ano de 2013 revela que o país, apesar de estar incorporando tecnologia e enfrentar a concorrência externa no mercado doméstico ${ }^{3}$, precisa ainda desenvolver instrumentos de

${ }^{3}$ O complexo agroindustrial sofreu significativos impactos nos anos 90 e 2000 (após
plano real) devido à concorrência externa que afetara a formação dos preços dos 
estímulo à produção consolidar a autossuficiência produtiva, tal como expressa o quadro de abastecimento de leite para o ano de 2013. Para este ano, a produção nacional projetada foi de 34.230 milhões de litros, para uma demanda de consumo de 35.266 milhões de litros e importação de 1.283 milhões de litros (MAPA, 2013).

Por sua vez, o Estado de São Paulo, no ano de 2012, participou com 5\% da produção nacional e 15\% da Região Sudeste no mesmo período (FERRAZ et. al., 2013). Neste estado, sistemas produtivos de pecuária leiteira são amplamente presentes em pequenas propriedades e se adaptam às características e dinâmica da agricultura familiar. Especialmente a região da Alta Paulista, recorte territorial do IBGE (Instituto Brasileiro de Geografia e Estatística), onde se insere o município de Dracena/SP, conta com 71.487 ha de estabelecimentos agropecuários, que juntos ofertam uma produção leiteira estimada de 2.200 mil litros.

Na região da Alta Paulista, especificamente em Dracena/SP, a comercialização leiteira é predominantemente realizada em arranjos cooperativos, com $76,5 \%$ dos produtores vinculados à associações ou cooperativas (SÃO PAULO, 2008). Tais estruturas são também consideradas favoráveis para promoção e disseminação de padrões produtivos e tecnológicos, além de se tornarem responsáveis por reunir a produção de pequenos produtores, armazenar e realizar testes preliminares de qualidade.

Especificamente, a associação em estudo atua na captação do leite nas propriedades, na a aferição de parâmetros preliminares de qualidade (como acidez e testes microbiológicos) e na refrigeração, disponibilizando tanques de expansão para uso dos associados.

Padrões tecnológicos distintos resultam em rentabilidade variável, decorrente dos níveis distintos de produção e produtividade de cada produtor. Pode-se entender que estas dimensões representam a resposta do produto obtido aos direcionadores de competitividade, como manejo, genética e sistema produtivo adotado. Por outro lado, o controle de qualidade captado nos testes preliminares (aferido por indicadores que expressam os atributos de qualidade intrínseca do leite) é adotado por força de regulamentações legais das autoridades sanitárias e exigência das indústrias compradoras. Assim, produção, produtividade, preços e custos, prêmios ou descontos de preços por qualidade se conjugam para compor a rentabilidade da atividade.

produtos lácteos no mercado doméstico. Já nos anos 2000 , a formação dos preços conta com razoável grau de coordenação por entidades de representação (BARROS, 2002). 
De maneira geral, para o segmento produtivo dos produtos agropecuários, os preços são formados em um mercado competitivo, característica bastante referenciada nos textos acadêmicos que tratam concorrência e mercados ${ }^{4}$. Especialmente no caso da cadeia produtiva do leite, o segmento produtivo é dotado de um padrão de concorrência no qual o produtor é entendido como pequeno em sua capacidade de negociar preços junto ao mercado comprador. Ou seja, no caso de sistemas de produção e comercialização com as características da produção e comercialização da pecuária leiteira, a formação dos preços ocorre em um mercado dado pela oferta de um grande número de produtores (e suas associações) em interação com um mercado comprador representado por pequeno número de indústrias de processamento agroindustrial (laticínios). Este mercado tem sofrido significativas transformações na última década, resultantes dos processos de fusões e aquisições entre indústrias processadoras. Este processo resulta em aumento do grau de concentração de mercado, assim fortalecendo as características de mercado oligopsônico ${ }^{5}$.

O controle e avaliação de custos de produção estão inseridos no escopo de gerenciamento financeiro da propriedade rural, destacando-se o conhecimento apropriado às especificidades da atividade, face às características do mercado comprador e as exigências impostas relativas ao volume ofertado e qualidade (MIRANDA et al. 2006). Sabbag et al. (2007) também destacam a necessidade de se ter uma gestão de custos como ponto fundamental para a viabilidade do agronegócio.

Para uma empresa agropecuária, o objetivo mais importante, sob o ponto de vista da administração, é o diagnóstico da situação da empresa e um planejamento eficaz (HOFFMANN et al., 1992), com a determinação de seus lucros ou prejuízos durante determinado período. Cada produtor, ou grupo de produtores, dispõe de suas próprias maneiras de realizar o diagnóstico de sua empresa ou de suas explorações produtivas. Assim espera-se que, quanto maior o volume de informações que um indivíduo ou grupo dispõe, mais efetivos serão os diagnósticos e avaliação dos resultados financeiros.

Entretanto, conforme aponta Peres et. al. (2008), informações sobre a rentabilidade e o risco de diferentes sistemas de produção são de extrema importância para o empresário rural, pois permitem a

\footnotetext{
${ }_{5}^{4}$ Como exemplo pode-se citar VASCONCELOS e GARCIA (2005).

5 Entre outros autores, tal movimento para a indústria de laticínios é discutido por CARVALHO e OLIVEIRA (2010); LIMA FILHO et. al. (2013).
} 
inovação e melhoria dos índices zootécnicos do rebanho, além de possibilitar maior rentabilidade na atividade.

Risco e a incerteza se associam a distintas interpretações (BODIE; MERTON; 2002). A incerteza existe quando não se tem conhecimento ao certo de quando ocorrerá tal fato, enquanto que o risco é o fato que realmente interfere nas tomadas de decisões. Portanto, a incerteza é uma condição necessária (não suficiente) para o risco, pois pode existir incerteza sem risco. Desta forma, a aplicação da análise de risco pode ser vista em diversas áreas do conhecimento, dentre as quais a da bovinocultura de leite.

Segundo Chen et. al. (2004), na necessidade de avaliar a empresa sob a perspectiva do risco, surge um problema de pesquisa: como evoluir as tomadas de decisões com base no gerenciamento dos custos? Desta forma, a presente pesquisa sugere aumentar o nível de controle dos custos para a produção leiteira mediante um maior domínio das variáveis que a influenciam.

Neste contexto, métodos que consideram distribuições de probabilidade, como os chamados métodos estocásticos ou probabilísticos, entre esses o Método de Monte Carlo, podem acrescentar informações relevantes para o processo de tomada de decisão em situações de risco e permitem análises simultâneas para diferentes variáveis, como preço, produção e custos, levando-se em consideração as distribuições de probabilidade (JANÉ, 2003).

Para tanto, o método de Monte Carlo é uma importante ferramenta para os produtores e/ou agentes tomadores de decisão, permitindo a investigação de algum problema com base na geração de números aleatórios, baseando-se no fato de que a frequência relativa de ocorrência de certo fenômeno aproxima-se da probabilidade econômica do mesmo, quando a experiência matemática é repetida várias vezes (JUNQUEIRA; PAMPLONA, 2002).

Desta forma, trabalhou-se inicialmente com duas hipóteses, dentre elas: a) as propriedades com menores volumes de produção de leite tendem apresentar menor rentabilidade econômica e b) as variáveis que mais impactam o resultado operacional são preço de venda do leite e volume produzido, em função da tecnologia no sistema produtivo.

Assim, o presente trabalho tem por objetivo avaliar indicadores financeiros para a produção de leite de um grupo de produtores pertencentes a uma associação do município de Dracena/SP, por meio da análise de custos de produção e rentabilidade, realizando-se estimativas pelo modelo estocástico 
(método de Monte Carlo), para determinação do risco da atividade frente às oscilações de preço e quantidade produzida.

\section{MATERIAL E MÉTODOS}

\subsection{Caracterização da região de estudo}

Os dados se reportam a sistemas de produção de leite da região da Alta Paulista no Estado de São Paulo e de produtores reunidos na Associação de Produtores Rurais de Dracena (APRD), cuja sede e respectivas propriedades são localizadas na mesma cidade.

A pesquisa foi realizada no período de agosto a novembro de 2012; em uma associação composta por 11 produtores de leite, que tem, na pecuária leiteira, a principal fonte de geração de renda. Considera-se que os sistemas de produção deste grupo são representativos dos padrões produtivos médios praticados na região da Alta Paulista.

Este trabalho, de natureza quantitativa, se classifica como exploratório, visa proporcionar melhor familiaridade com o problema, com vistas a torná-lo mais explícito; e descritivo, no sentido de sua origem estar associada à observação, registro, analise e correlações entre fenômenos ou fatos, sem interferir no ambiente analisado. Ainda assim, houve uma abordagem qualitativa, em que 0 pesquisador procurou aprofundar-se na compreensão dos fenômenos que estuda. Richardson (1999) propõe que a pesquisa quantitativa é também qualitativa, pois não importa como foram efetuadas as medidas, pois o que é medido continua a ser uma qualidade.

\subsection{Estrutura de custos e análise de riscos}

A presente pesquisa baseou-se na aplicação de entrevistas junto a cada produtor do grupo associativo abordado; o conjunto destas viabilizou o levantamento dos coeficientes técnicos de produção (Tabela 1). Como procedimento inicial, foi realizada estimativas e análise de custos de produção através da metodologia do custo operacional total (COT) proposta por Matsunaga et al. (1976). Após estimativas de custos, foram calculados os indicadores de rentabilidade, referenciados por Martin (1997).

Os preços praticados foram expressos em Reais ( $R \$)$, durante o período primavera-verão, período que, segundo os 
padrões de variação estacional de produção, possibilita maior oferta de leite, e custos relativamente menores em razão da menor necessidade relativa de suplementação com ração, dada a maior frequência de chuvas e disponibilidade hídrica e, em decorrência desta, boa qualidade das pastagens.

A análise de custos e preços torna possível estimar o ponto de equilíbrio da atividade, que se refere ao indicador de volume mínimo que se deve produzir (quantidade) para cobrir os custos de produção da atividade.

Tabela 1 - Indicadores para análise de custos e rentabilidade.

\begin{tabular}{|c|c|c|}
\hline \multirow{3}{*}{$\begin{array}{l}\text { Indicador Financeiro } \\
\text { Indicadores de Custos } \\
\text { Custo Operacional Efetivo }\end{array}$} & Unidade & Coeficientes utilizados \\
\hline & & \\
\hline & COE & $\begin{array}{l}\text { Mão de obra } \\
\text { mecanizada (hora- } \\
\text { máquina) e/ou manual } \\
\text { (hora-homem), } \\
\text { insumos (sacas, } \\
\text { toneladas e doses) e } \\
\text { energia elétrica (KWh). }\end{array}$ \\
\hline Custo Operacional Total & COT & $\begin{array}{l}\text { COE + depreciação de } \\
\text { máquinas } \\
\text { equipamentos (método } \\
\text { linear), } \\
\text { despesas ( } 5 \% \text { do COEtras) } \\
\text { e juros de custeio } \\
(8,75 \% \text { a.a. sobre } 50 \% \\
\text { do COE), referencial } \\
\text { para programas de } \\
\text { crédito de custeio } \\
\text { agrícola. }\end{array}$ \\
\hline $\begin{array}{l}\text { Indicadores de Rentabilidade } \\
\text { Receita Bruta }\end{array}$ & RB & $\begin{array}{l}\text { Produção (leite) } \\
\text { Preço recebido }\end{array}$ \\
\hline Lucro Operacional & LO & RB - COT \\
\hline Indice de Lucratividade & $\mathrm{IL}$ & $(\mathrm{LO} / \mathrm{RB}) \times 100$ \\
\hline
\end{tabular}


A abordagem probabilística da análise de riscos para a atividade leiteira envolveu a simulação de variáveis selecionadas, com suas distribuições de probabilidade. Para tanto, fez-se uso do Método de Monte Carlo, através do software Crystal Ball (Oracle ${ }^{\circledR}$ ) aplicado na plataforma Microsoft Office Excel ${ }^{\circledR}$.

O método de Monte Carlo consiste no fato de que a frequência relativa de ocorrência do acontecimento de certo valor tende a aproximar-se da probabilidade de ocorrência desse mesmo valor, quando a experiência é repetida várias vezes, considerando a geração de números aleatórios (Hertz, 1964 apud Ponciano et al., 2004). Assim, permite resolver uma quantidade de problemas com a simulação de cenários e o posterior cálculo de um valor esperado; neste caso em específico, do LO, diante das possíveis escolhas acerca das variáveis mais relevantes de risco com relação à produção de leite.

Destaca-se que a simulação de Monte Carlo oferece muitas vantagens, dentre as quais: o computador realiza todo trabalho de geração dos valores aleatórios; a validade da teoria da simulação é amplamente reconhecida, o que permite que seus resultados sejam facilmente aceitos e alterações no modelo podem ser feitas rapidamente e os novos resultados podem ser comparados com os anteriores.

Sua operacionalização baseia-se inicialmente na construção de um modelo determinístico, considerando-se os indicadores de rentabilidade para cada produtor. Em seguida, constrói-se um modelo com as principais incertezas relativas aos variáveis estudadas, usando distribuições de probabilidades. Em terceiro lugar, são especificadas as relações entre as variáveis de entrada e, por último, é executada a simulação propriamente dita, por meio de alguns aplicativos de mercado (CARDOSO; AMARAL, 2000).

Ainda segundo os autores, as desvantagens da simulação residem nas dificuldades em se estimar as relações existentes entre as variáveis, em se definir os formatos das distribuições de probabilidades das variáveis que melhor representem a realidade, e em se interpretar uma distribuição a partir dos resultados gerados, algo que muitas vezes um gestor não está apto a fazer.

Nesta estrutura, as seguintes etapas na análise foram respeitadas: a) identificação da distribuição de probabilidade de cada uma das variáveis que alteram a rentabilidade da produção leiteira, tomando-se os parâmetros custos, preço pago ao produtor e produção leiteira/ciclo; b) seleção ao acaso, de um valor para cada variável simulada, a partir das distribuições de probabilidade, sendo 
utilizadas as funções triangular ${ }^{6}$ (produção e custos) e normal ${ }^{7}$ (preço); c) cálculo do lucro operacional, com a utilização das variáveis obtidas no processo de simulação do método de Monte Carlo; e d) repetição do processo para obter a probabilidade de insucesso a partir da distribuição normal dos resultados. Para obtenção de um resultado confiável e significativo foram realizadas 10.000 iterações $^{8}$ dos dados. Adicionalmente, apresentam-se algumas inferências da estatística descritiva para complementar o método em análise.

Vale ressaltar que a distribuição de probabilidade referente aos dados de cada variável foi definida pelos autores da pesquisa, em função da coleta de dados primários para análise entre as propriedades diagnosticadas. Consideraram-se três variáveis de entrada (independentes) e distribuições, adotando-se a distribuição triangular e normal, contendo: a) custos de produção, tomando-se como mínimo de $R \$ 875,22$, a mais provável de $R \$ 2.775,00$ e o máximo de $R \$ 4.674,77$; b) produção por ciclo mensal para o mínimo de 600 litros, a mais provável de 4.800 litros e o máximo de 9.000 litros e, c) o preço pago, em consonância com o preço médio recebido pelos produtores da região e praticado à época do levantamento dos dados da pesquisa (agosto de 2012) em $R \$$ $0,80 /$ litro $^{9}$, com um desvio de até $\mathrm{R} \$ 0,15$, para o mês de agosto de 2012.

Com tais configurações, foi possível verificar a probabilidade de sucesso ou fracasso da produção leiteira pelo grupo associativo, a partir da frequência de distribuição dos parâmetros em análise e as inferências estatísticas de maior relevância à variável dependente (LO), para melhor elucidar o método. Em síntese, a análise de sensibilidade baseou-se na criação de cenários produzidos por meio da simulação de Monte Carlo; desta forma, foi possível estipular o intervalo de valores (aleatórios) a que cada variável independente poderia associar-se, considerando os respectivos parâmetros e distribuições definidos.

\footnotetext{
${ }^{6}$ A função triangular refere-se à distribuição de probabilidade contínua que possui um valor mínimo, um valor máximo e uma média para cada variável de análise.

${ }^{7}$ Descrita pelos parâmetros média e desvio padrão para cada variável de análise.

${ }^{8}$ Número de repetições.

${ }^{9}$ Valor correspondente também à média histórica de preços nominais (2009-2013) para

o leite no mês de Agosto, segundo o IEA (Instituto de Economia Agrícola).
} 


\section{RESULTADOS E DISCUSSÃO}

Da composição dos custos enfrentados pelos produtores na produção leiteira, os maiores dispêndios são explicados com aquisição de insumos, que representam $57 \%$ do COE (custo operacional efetivo). Nesta categoria de despesa, a maior participação relativa foi para custo com milho (25,7\% dos insumos). Já a mão de obra representou $43 \%$ do COE, sendo que as atividades manuais para ordenha expressaram $83 \%$.

O perfil genético do rebanho leiteiro é definido pelas características de raça predominante, a Girolando, que apresenta características de desempenho adaptáveis às condições climáticas da região. A alimentação é realizada em regime de pasto, com arraçoamento suplementar a base de energético e proteinado como cana de açúcar, farelo de soja, milho e sal. A suplementação de concentrado constitui prática frequente em $45,5 \%$ das propriedades do grupo abordado.

Práticas sanitárias como vacinação e vermifugação do rebanho são procedimentos obrigatórios efetuados pelos produtores e contidos na composição dos insumos, assim como o uso de medicamentos para o controle de endo e ectoparasitas e o controle preventivo de mastite nas vacas leiteiras.

Os resultados da composição dos custos encontram-se relacionados na Tabela 2 e identificam a participação dos principais grupos de dispêndios componentes dos custos de produção. As categorias de dispêndios de maior relevância para a composição da infraestrutura produtiva foram: animais (42,23\%), máquinas $(25,00 \%)$ e galpão (24,39\%), com pequenas variações na participação de cada categoria. A depreciação representou em média de 19\% do COE, correspondente à parcela de custo fixo da atividade produtiva. 
Tabela 2 - Participação das principais categorias de despesas na composição dos custos totais dos produtores da APRD - Nova Alta Paulista Dracena/SP; 2012.

\begin{tabular}{rrrr}
\hline Produtor & $\begin{array}{r}\text { Mão de Obra } \\
\text { (COE) }\end{array}$ & $\begin{array}{r}\text { Insumos } \\
\text { (COE) }\end{array}$ & $\begin{array}{r}\text { Depreciação } \\
\text { (COT) }\end{array}$ \\
\hline 1 & $22 \%$ & $78 \%$ & $25 \%$ \\
2 & $32 \%$ & $68 \%$ & $15 \%$ \\
3 & $59 \%$ & $41 \%$ & $20 \%$ \\
4 & $68 \%$ & $32 \%$ & $30 \%$ \\
5 & $37 \%$ & $63 \%$ & $18 \%$ \\
6 & $33 \%$ & $67 \%$ & $17 \%$ \\
7 & $53 \%$ & $47 \%$ & $9 \%$ \\
8 & $63 \%$ & $37 \%$ & $13 \%$ \\
9 & $34 \%$ & $66 \%$ & $8 \%$ \\
10 & $35 \%$ & $65 \%$ & $27 \%$ \\
11 & $38 \%$ & $62 \%$ & $28 \%$ \\
\hline Média & $\mathbf{4 3 \%}$ & $\mathbf{5 7 \%}$ & $\mathbf{1 9 \%}$ \\
\hline
\end{tabular}

Fonte: dados da pesquisa.

A avaliação conjunta da produção, da receita obtida com a comercialização do leite e indicadores de rentabilidade (Lucro Operacional, Índice de Lucratividade e Ponto de Equilíbrio da produção leiteira) para conjunto dos 11 produtores foram viabilizados pelo levantamento de custos e os indicadores encontram-se dispostos na Tabela 3.

Destaca-se que o Lucro Operacional (LO) foi resultante da diferença entre a receita bruta (RB) e os custos totais; e o Índice de Lucratividade (IL) representou a proporção da receita bruta que se constitui em recursos disponíveis, após a cobertura dos custos totais, por meio da expressão IL = LO/RB x 100. Para o ponto de equilíbrio em relação à quantidade, foi obtido pela razão entre os custos totais e o preço pago ao produtor $\left(R \$ 0,80\right.$ litro $\left.^{-1}\right)$.

Do grupo associativo, constatou-se que $63,6 \%$ dos produtores (7 de 11 produtores) auferiram resultados desfavoráveis, revelados por lucro operacional negativo. Os valores negativos expressam resultados da baixa produção mensal frente a custos operacionais relativamente elevados para manter a atividade. Este resultado sinaliza para uma possível necessidade de melhoria nos padrões tecnológicos nos sistemas produtivos regionais, e em particular para quase $64 \%$ do grupo associativo estudado. 
Tabela 3 - Custo Operacional Total (COT), Receita Bruta (RB), Lucro Operacional (LO), Índice de Lucratividade (IL) e Ponto de Equilíbrio da produção de leite, Nova Alta Paulista (APRD Dracena/SP), 2012.

\begin{tabular}{|c|c|c|c|c|c|c|}
\hline Prod. & $\begin{array}{l}\text { Produção } \\
\text { (litros mês'-1) }\end{array}$ & $\begin{array}{l}\text { COT } \\
\text { (R\$) }\end{array}$ & $\begin{array}{r}\mathbf{R B} \\
(\mathbf{R} \$)\end{array}$ & $\begin{array}{l}\text { LO* } \\
\text { (R\$) }\end{array}$ & $\begin{array}{l}\text { IL } \\
(\%)\end{array}$ & $\begin{array}{l}\text { Ponto de } \\
\text { Equilíbrio } \\
\text { (litros) }\end{array}$ \\
\hline 1 & 9000 & $4.674,77$ & $7.200,00$ & $2.525,23$ & 35,07 & 5843 \\
\hline 2 & 600 & 875,22 & 480,00 & $(395,22)$ & - & 1094 \\
\hline 3 & 1200 & $1.776,96$ & 960,00 & $(816,96)$ & - & 2221 \\
\hline 4 & 1560 & $1.737,97$ & $1.248,00$ & $(489,97)$ & - & 2172 \\
\hline 5 & 6600 & $4.181,36$ & $5.280,00$ & $1.098,64$ & 20,81 & 5227 \\
\hline 6 & 3600 & $2.806,11$ & $2.880,00$ & 73,89 & 2,57 & 3508 \\
\hline 7 & 1500 & $1.532,41$ & $1.200,00$ & $(332,41)$ & - & 1916 \\
\hline 8 & 1500 & $1.577,01$ & $1.200,00$ & $(377,01)$ & - & 1971 \\
\hline 9 & 3000 & $2.872,43$ & $2.400,00$ & $(472,43)$ & - & 3591 \\
\hline 10 & 5100 & $3.028,43$ & $4.080,00$ & $1.051,57$ & 25,77 & 3786 \\
\hline 11 & 3600 & $3.160,71$ & $2.880,00$ & $(280,71)$ & - & 3951 \\
\hline
\end{tabular}

*Valores monetários entre parênteses indicam prejuízo à atividade.

Fonte: dados da pesquisa.

Para Simões et al. (2009), sistemas mais especializados produzem o suficiente para tornar os custos unitários menores do que os custos praticados nos sistemas de menor volume de produção (por unidade de área ou unidade animal), menos tecnificados e com baixa utilização de uso de insumos. Assim, para o grupo associativo analisado, pode-se inferir que o padrão tecnológico de proporção considerável dos produtores necessita ser reavaliado com vistas a incorporar tecnologias inovadoras, da mesma forma os resultados sinalizam a necessidade de rever conceitos de gerenciamento da produção leiteira.

Em relação à produção média dos produtores abordados na pesquisa, esta foi de 112,91 litros dia $^{-1}$. Segundo a avaliação de Zoccal (2012), segmentos produtivos com oferta entre 50 a 200 litros por dia estão entre os mais frequentes entre a média dos demais segmentos para a região Sudeste do Brasil. Entretanto, para o grupo produtivo analisado, a área total média destinada para a pecuária leiteira foi de 11,7 ha, sugestiva de produção em sistemas de natureza familiares, mas que limitam a busca por ganhos de escala com redução de custos na produção leiteira. 
O valor médio da produtividade da mão de obra presente no sistema associativo abordado foi de 76,32 litros-homem dia ${ }^{-1}$ para ordenha manual. Segundo Costa (2007), sistemas produtivos da pecuária leiteira com níveis de produtividade da mão de obra considerados bons são aqueles com valores superiores a 200 litroshomem dia $^{-1}$. Por este critério, o grupo associativo estudado tem seus sistemas produtivos distinguidos por produtividade aquém do desejável.

Do conjunto de produtores avaliados, apenas quatro ou em termos relativos, $36 \%$ auferiram resultados positivos expressos pelo índice de lucratividade, o que corresponde a dizer que a produção média entre estes foi superior a $32 \%$ da quantidade mínima necessária para cobertura de seus custos totais. O índice de lucratividade reflete o quanto o sistema produtivo auferiu lucro para cada $R \$ 100,00$ de vendas efetuadas. Quanto maior for o resultado, mas atrativo para o produtor; para o grupo analisado, melhores resultados foram obtidos para os produtores 1 e 10, sendo o produtor 6 aquele que desfruta da menor margem de lucratividade.

O método de Monte Carlo permite realizar um conjunto de interações para variáveis simultâneas e possibilita a indicação de cenários que simulam 0 quanto os resultados podem variar (KELLIHER; MAHONEY, 2000). Por este tem-se primeiramente a variável-resposta Lucro Operacional (LO), decorrente da adoção das variáveis de análise custos, os preços recebidos e a produção para identificação da distribuição de probabilidade. Neste caso o LO médio foi de $R \$ 1.081,29^{10}$, representando $71,77 \%$ de probabilidade de ser positivo (Figura 1), segundo as respectivas distribuições de frequências apresentadas.

\footnotetext{
${ }^{10}$ Destaca-se que este valor foi gerado mediante uma simulação estocástica de 10.000 iterações pelo software Crystal Ball, considerando o conjunto de variáveis concomitantes em análise, o que difere de um valor calculado pelo método determinístico para uma dada situação.
} 


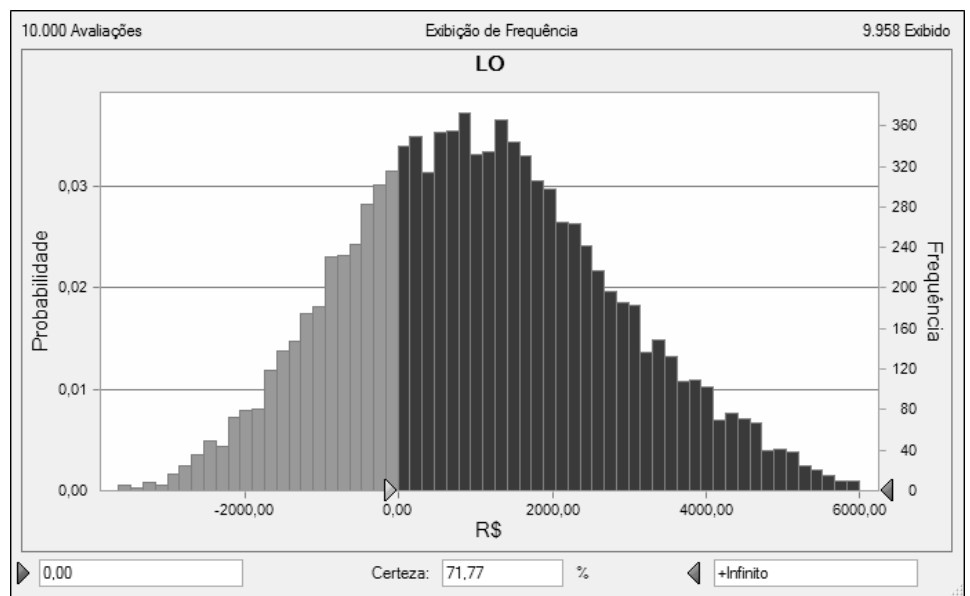

Figura 1 - Diagrama de frequência para o lucro operacional (distribuição normal), obtida pela simulação de Monte Carlo (Crystal Ball software).

Outro resultado do modelo adotado refere-se à indicação da probabilidade de insucesso da atividade da produção leiteira, evidencias da pela expressão (1) abaixo:

$P(L O \geq 0)=0,718 \leftrightarrow(L O<0)=1-0,718 \leftrightarrow P(L O<0)=28,2 \%$

Ou seja, pode-se supor que um grau de risco considerável encontra-se inerente aos padrões tecnológicos presentes nos sistemas produtivos do grupo de produtores estudado, expresso pela probabilidade de $28 \%$ de fracasso para a atividade ${ }^{11}$. Para Casarotto Filho e Kopittke (2000), a preocupação com o risco é maior quando as variações podem trazer prejuízo à atividade (como índices de LO negativos), tal como se observa para sete dos onze produtores, uma considerável proporção do grupo analisado (Tabela 2) e pela distribuição de frequência do LO (Figura 1). Segundo Mariotti (2013), incerteza e risco são conceitos distintos. O risco pode ser avaliado, calculado, estimado em termos de probabilidades e apresentado sob a forma de modelos matemáticos/estatísticos, como se traduz no referido estudo; no caso da incerteza, não sabemos lidar com ela de

\footnotetext{
${ }^{11}$ Para aferir com maior precisão a associação entre padrão tecnológico, risco e a probabilidade de fracasso da atividade, seria necessário estratificar os produtores em tipologias de padrões tecnológicos definidos, o que não encontra-se no escopo deste trabalho.
} 
modo quantitativo, de maneira que a expressão "gestão da incerteza" pouco ou nada significa em termos práticos.

De acordo com estudo realizado por Haddade et al. (2006), as variáveis que mais afetaram a rentabilidade da bovinocultura de leite estavam relacionadas com o preço do leite, venda de animais, alimentação do rebanho e mão de obra, estes últimos elementos integrantes do custo operacional efetivo. Em consonância com Oliveira et. al. (2007), observa-se que houve uma probabilidade de $33,08 \%$ de risco para produtores com até 150 litros dia ${ }^{-1}$, resultando em valores próximos do referido estudo.

Ainda quanto ao método de Monte Carlo, através da análise de regressão, os itens de maior sensibilidade na expressão da distribuição de frequência do LO foram a quantidade produzida e preço, respectivamente com 0,646 e 0,162, considerados a um nível de significância de $\alpha=5 \%$. Estes valores relativos foram resultantes das variáveis que mais contribuíram à sensibilidade do LO, gerados pelo software, ou seja, estes valores positivos sinalizam existir relação direta entre as variáveis; por exemplo, caso ocorra um aumento de $10 \%$ na quantidade de leite, haverá um aumento de $6,5 \%$ sobre o LO; da mesma forma, um aumento de $10 \%$ do preço pago ao produtor, ocasionará um aumento de 1,6\% sobre o LO. Assim, recomenda-se maior atenção ao gerenciamento para mitigação dos riscos que afetam a produção e produtividade, uma vez que o produtor tem pouco alcance sobre os fatores intervenientes na variabilidade de preços. Os resultados estatísticos de análise para o Lucro Operacional, pelo método de Monte Carlo, encontram-se na Tabela 4.

Tabela 4 - Parâmetros estatísticos para o Lucro Operacional, decorrentes do processo de simulação estocástica por Monte Carlo.

\begin{tabular}{lr}
\hline Estatística & Valores de previsão \\
\hline Avaliações (iterações) & 10.000 \\
Média & $\mathrm{R} \$ 1.057,19$ \\
Mediana & $\mathrm{R} \$ 972,94$ \\
Curtose & 2,89 \\
Assimetria & 0,2520 \\
Mínimo & $\mathrm{R} \$-3.665,70$ \\
Máximo & $\mathrm{R} \$ 7.715,95$ \\
\hline
\end{tabular}

Fonte: dados da pesquisa. 
A leitura estatística apresentada pelo modelo mostrou também uma assimetria de 0,2520 (positiva), reforçando que a média obtida no modelo para o LO $(\mathrm{R} \$ 1.057,19)$ foi maior que a mediana ( $R \$ 972,94)$; e a curtose foi de 2,89 , indicando distribuição na curva normal de maneira platicúrtica (menor probabilidade que a curva normal apresenta de possuir valores próximos à média), com maior ocorrência de desvios para o LO esperado, aumentando-se desta forma o risco da atividade, sob as condições dos sistemas produtivos em análise.

O risco decorrente do Lucro Operacional (LO), com probabilidade limitada a apenas $28,23 \%$ de não ser superior a zero, é também evidenciado diretamente no Índice de Lucratividade (IL) por Monte Carlo, apresentando média de 10,12\% em uma distribuição de frequência, reforçando as limitações da atividade, em contraposição com índices ao redor de $20 \%$ para um melhor nível de eficiência entre produtores de leite, conforme Silva et. al. (2010).

Os resultados probabilísticos indicaram a produção como principal fator limitante e determinante para obtenção de índices de lucratividade desejáveis para os produtores, expondo a identificação de apenas quatro com percentuais de IL positivos para a atividade, inferindo que a produção média necessária para viabilizar a atividade foi estimada em 6.075 litros de leite mês $^{-1}$, conforme ilustra a Figura 2.

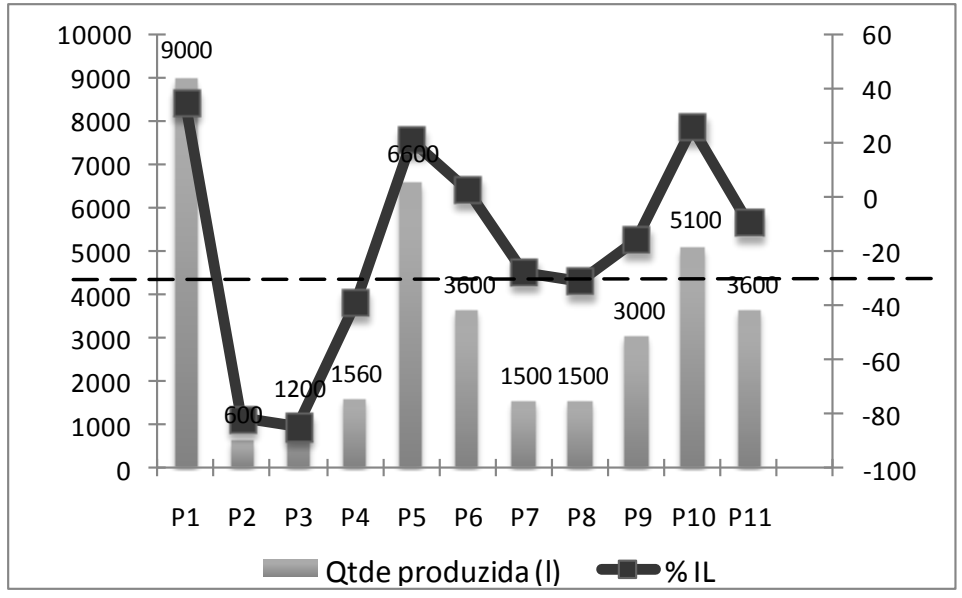

Figura 2 - Quantidade produzida (litros/ano) X Índice de lucratividade da produção de leite, Nova Alta Paulista (APRD Dracena/SP), 2012. 
Os padrões tecnológicos são constituídos pela combinação dos fatores de produção incluindo os insumos de capital fixo e semifixo, trabalho e os insumos que entram no sistema de um ciclo de produção. Os indicadores obtidos para o grupo associativo analisado revelam alta variabilidade da lucratividade, que pode ser explicada em decorrência dos diferentes padrões tecnológicos existentes entre os produtores, e, por extrapolação, entre os produtores da região de Dracena, sinalizando para a necessidade de um planejamento voltado para reduzir custos.

O conjunto de informações apresentado pode auxiliar os produtores no acesso às informações econômicas inerentes a atividade leiteira, com vistas a melhoria no processo de gestão no sistema de produção. Revisões no sistema de produção, sobretudo visando à melhoria no manejo e qualificação da mão de obra, podem resultar em resposta positiva na rentabilidade da atividade, dada a importância desta na composição dos custos operacionais e já que a probabilidade de auferir resultados negativos foi identificada como potencialmente presente.

\section{CONCLUSÕES}

Para os produtores associativos, os maiores custos são relacionados aos insumos e mão de obra, sendo este último com maior expressividade para a análise de riscos pelo método de Monte Carlo.

Apenas $36 \%$ dos produtores apresentaram índice de lucratividade superior a zero, correspondendo a uma produção superior em $32 \%$ à quantidade mínima para cobertura dos custos.

Sob a ótica da gestão de riscos, a atividade mostrou-se limitada quanto à viabilidade de suas operações. A produção e o preço caracterizaram variáveis de maior expressividade, inferindo que os resultados econômicos tornaram-se restritos para um grupo associativo.

Assim, cenários de riscos exemplificados pela técnica de Monte Carlo tornam possível melhorar a tomada de decisão nas organizações frente às contingências ambientais, exigindo-se maior volume de produção que minimize o custo gerado pelo sistema adotado, tendo em vista que o produtor não tem capacidade de interferir na formação do preço pago pelo seu produto, pois os preços são formados em um mercado oligopsônico composto pelos laticínios compradores. 
Existe a possibilidade em futuras pesquisas de expansão acerca de Monte Carlo, incorporar novas variáveis não limitadas apenas à administração financeira, que aprofundem a compreensão dos fatores qualitativos e quantitativos sobre a produção leiteira.

\section{REFERÊNCIAS}

BRASIL. Ministério da Agricultura, Pecuária e Abastecimento. Projeções do Agronegócio: Brasil 2012/2013 a 2022/2023. Assessoria de Gestão Estratégica. Brasília: Mapa/ACS, 2013. 96 p.

BARROS, G.S.A.C; GALAN, V.B; GUIMARÃES, V.D.A; BACCHI, M.R.P. Sistema Agroindustrial do leite no Brasil. Brasília: Embrapa, 2002. 170p.

BODIE, Z.V.I.; MERTON, R. Finanças. 2 ed. São Paulo: Bookman, 2002, p.259.

CARDOSO, D; AMARAL, H.F. O uso da simulação de monte carlo na elaboração do fluxo de caixa empresarial: uma proposta para quantificação das incertezas ambientais. Anais.. ENEGEP, 2000. Disponível em: <http://www.abepro.org.br/biblioteca/enegep2000_e0159.pdf>. Acesso em: 18 Nov. 2014.

CARVALHO, G.R; OLIVEIRA, C. Indústria de Laticínios: Brasil no contexto internacional. Revista Agroanalysis (FGV). Vol. 30, n.08. 2010.

CASAROTTO FILHO, N. C. \& KOPITTKE, B. H. Análise de Investimentos: matemática financeira, engenharia econômica, tomada de decisão e estratégia empresarial. 9 ed. São Paulo: Atlas, 2000 .

CHEN, I.J. ; PAULRAJ, A.; LADO, A., Strategic Purchasing, Supply Management and firm performance, Journal of Operations Management, Vol. 22, No. 5, 2004.

COSTA, J. L. Avaliação de indicadores técnicos de eficiência e renda da propriedade leiteira. In: Tecnologias para 0 desenvolvimento da pecuária de leite familiar do norte de Minas e Vale do Jequitinhonha. Juiz de Fora: Embrapa Gado de Leite, 2007, p. 39-51.

FERRAZ, J. V. et al. (Coord.). Anualpec 2013: anuário da pecuária brasileira. 20ํㅡㄹ ed. São Paulo: FNP, 2013. 
HADDADE, I. R; SOUZA, P.M; BARROS, E.E.L; ALVES, G.R; SCOLFORO, L; CORDEIRO, M.D; PERES, A.A.C; HENRIQUES, L.T. Avaliação econômica sob condições de risco em sistema produtivo de gado de leite na região Norte do Estado do Rio de Janeiro. Arquivo Brasileiro de Medicina Veterinária e Zootecnia, v. 57, p. 361-366, 2005.

HOFFMANN, R; ENGLER, J.J.C.; SERRANO, O; THAME, A.C.M.; NEVES, E.M. Administração da empresa agrícola. 7a ed. São Paulo: Pioneira Ed., 1992, 325p.

JANÉ, D.A. A simulação de monte carlo e a lógica fuzzy na análise econômico/financeira de investimentos sob condições de risco. Programa de pós-graduação em engenharia de produção. UNIFEl, 2003 (Dissertação). $157 \mathrm{f}$.

JUNQUEIRA, K.C., PAMPLONA, E. O. Utilização da Simulação de Monte Carlo em estudo de viabilidade econômica para a instalação de um conjunto de rebeneficiamento de café na COCARIVE. XXII Encontro Nacional de Engenharia de Produção, Curitiba/PR, 2002.

KELLIHER, C. F.; MAHONEY, L. S. Using Monte Carlo Simulation to improve long-term investment decisions. The Appraisal Journal, Chicago, v. 68, n. 1, 2000, p. 41-56.

LIMA FILHO, R.R; AGUIAR, G.A.M; TORRES, A. Setor Leiteiro: 2013 será ano de recuperação. Revista Agroanalysis (FGV). Vol. 33, n.06. 2013.

MARIOTTI, H. Incerteza e risco. In: Complexidade e sustentabilidade: o que se pode e o que não se pode fazer. São Paulo, Atlas, 2013, 262 p.

MARTIN N.B, SERRA R, OLIVEIRA M.D.M, ANGELO J.A, OKAWA $\mathrm{H}$. Sistema integrado de custos agropecuários - CUSTAGRI. Informações Econômicas, São Paulo, v. 28, n. 1, 1998, p.7-28.

MATSUNAGA M, BEMELMANS P.F; TOLEDO P. Metodologia de custo de produção utilizado pelo IEA. Agricultura em São Paulo, São Paulo, v. 23, n. 1, 1976, p. 123-139.

MIRANDA E.E; CRISCUOLO, C; QUARTAROLI, C.F. Desenvolvimento rural: gestão territorial. Revista Agroanalysis (FGV), São Paulo, v. 26, n. 7, 2006, p.40. 
OLIVEIRA, E.R; NORONHA, J.F; FIGUEIREDO, R.S; SILVA JUNIO, R.P. Estudo de rentabilidade econômica, sob condição de risco, para três sistemas produtivos de bovinocultura de leite em Piracanjuba - GO. Anais SOBER 2007. Disponível em $<$ http://www.sober.org.br/palestra/6/545.pdf>. Acesso em 24 Nov. 2014.

PERES, A.A.C; SOUZA, P.M; VASQUEZ, H.M; SILVA, J.F.C; CARVALHO, C.A.B; CARVALHO, J.B.P; MORENZ, M.J.F. Análise financeira sob condições de risco de sistemas de produção de leite na região do vale do paraíba/SP. Boletim da Indústria Animal, N. Odessa, v.65, n.1, 2008. p. 35-42.

PONCIANO, N.J; SOUZA, P.M; MATA, H.T.C; VIEIRA, J.R; MORGANO, I.F. Análise de viabilidade econômica e de risco da fruticultura na região norte Fluminense. Revista de Economia e Sociologia Rural, Brasília, v. 42, n. 4, 2004, p. 615-635.

RICHARDSON, R. J. Pesquisa social: métodos e técnicas (3a ed.). São Paulo: Atlas, 1999.

SABBAG, O.J; ROZALES, R.R; TARSITANO, M.A.A; SILVEIRA, A.N. Análise econômica da produção de tilápias (Oreochromis niloticus) em um modelo de propriedade associativista em llha Solteira/SP. Custos e Agronegócio on line, Recife, v. 3, n. 2, 2007, p. 86-100.

SÃO PAULO (Estado). Secretaria de Agricultura e Abastecimento. Coordenadoria de Assistência Técnica Integral. Instituto de Economia Agrícola. Levantamento censitário de unidades de produção agrícola do Estado de São Paulo - LUPA 2007/2008. São Paulo: SAA/CATI/IEA, 2008. Disponível em: <http://www.cati.sp.gov.br/projetolupa>. Acesso em: 20 Mar. 2014.

SILVA, F. D. V; CARVALHO, R. M; CAMPOS, R. T. Eficiência e rentabilidade da produção de leite no Estado do Ceará: uma aplicação de fronteira estocástica. Revista de Economia e Sociologia Rural, Brasília: SOBER, 2010, p.1-22.

SIMÕES, A.R.P; SILVA, R.M; OLIVEIRA, M.V.M; CRISTALDO, R.O; BRITO, M.C.B. Avaliação econômica de três diferentes sistemas de produção de leite na região do Alto Pantanal Sul-mato-grossense. Revista Agrarian, Dourados, v. 2, n. 5, 2009, p. 153-167.

VASCONCELLOS, M. A.; GARCIA, M. E. Fundamentos de economia. 2. ed. São Paulo: Saraiva, 2005. 
ZOCCAL, R. Quantos são os produtores de leite no Brasil? Embrapa - Panorama do Leite, № 64, 2012. Disponível em $<\mathrm{http}: / / w w w . c i l e i t e . c o m . b r / s i t e s / d e f a u l t / f i l e s / C o n j u n t u r a \_2012 \_03 . p d f$ >. Acesso em: 20 Mar. 2014. 